\title{
Effects of COVID-19 Pandemic on General Surgical Emergencies Priorities
}

\author{
Adel Mohamed Khalaf ${ }^{1}$ MD., Gamal Galal Al-Shimy ${ }^{1}$ MD., Esam Mahmoud Osman ${ }^{1}$ MD.
}

\section{* Corresponding Author: \\ Adel Mohamed Khalaf \\ Adelkhalaf749.el@azhar.edu.eg}

\section{Received for publication November 19, 2021; Accepted Junary 24, 2022;}

Published online Junary 24, 2022.

Copyright The Author published by Al-Azhar University, Faculty of Medicine, Cairo, Egypt. Users have the right to read, download, copy, distribute, print, search, or link to the full texts of articles under the following conditions: Creative Commons Attribution-Share Alike 4.0 International Public License (CC $B Y-S A$ 4.0).

doi: 10.21608/aimj.2022.106961.1669

${ }^{I}$ Department of General Surgery, Faculty of Medicine, Al-Azhar University (Assuit), Egypt

\begin{abstract}
Background: Since the occurrence of COVID-19 pandemic, global significant stress on healthcare programs to identify severity and mortality rate.

Aim of the work: The present article concentrates on emergency acute general surgical duties possessed to implement the spread of COVID-19.

Patients and Methods: In COVID-19 epidemic period from March 2018 to July 2021 files of all patients who underwent emergency surgery in the departments of General Surgery, Al-Azhar University HospitalAssiut were followed and reviewed. All cases requiring surgical interference in "emergency surgery". Cases subjected urgent procedures during (2020 and 2021) as "Pandemic Group" and during (2018 and 2019) as "Control Group".

Result: Within the two eras, 770 cases $(590+180)$, comprising 293 cases $(102+116+50+25)$ who underwent emergency surgery and 477 patients $(188+184+80+25)$ who were observed non-operatively, were included in the present study. There was $37 \%$ of the patients $(102+116 / 590)$ underwent surgery in the control group and $42 \%$ of the pandemic group $(50+25 / 180)$ underwent surgery. There was a $65.6 \%(143 / 218)$ reduction in the number of emergency surgeries and $61.4 \%$ (267/372) decline in the observational managed cases of the pandemic series.

Conclusion: This article aims to tool up proper directions to undergo urgent surgery in a protected and safe medium for both healthcare professionals and patients during COVID-19 attach displayed the most significant directions for COVID-19 victim's requirements for urgent operative management. Thus advising checking of COVID-19 contagion in emergency expecting urgent interference. We advise keeping the suspected patient in isolation till PCR result is available, and to treat the patient as a case of overt COVID.
\end{abstract}

Keywords: COVID-19 pandemic; surgical emergencies; outcomes.

Disclosure: The authors have no financial interest to declare in relation to the content of this article. The Article Processing Charge was paid for by the authors.

Authorship: All authors have a substantial contribution to the article.

\section{INTRODUCTION}

All over the history and among societies, pandemics have been caused by infectious diseases. Infectious diseases arising and re-arising and occurring at unpredictable speed. Thanks to the World Health Organization (WHO), global emergence of disease epidemics and outbreaks caused by more than 20 agents over the past decade. Novel infectious agents cause some of these epidemics such as H1N1 and MERS-CoV (the novel coronavirus).

This new coronavirus (COVID-19) affecting humans became the 5th pandemic recorded after flu pandemic of 1915. Coronavirus initially isolated in China (Wuhan district), with subsequent invasion all over the globe. Official name of coronavirus is SARS-CoV-2 (severe acute respiratory syndrome coronavirus 2). It is considered to be of an animal coronavirus origin. The ability of man-to-man infection was adapted. As it has high infectivity, this is why spread rapidly with continuous strain changes in the human race. ${ }^{2}$
The COVID-19 pandemic virus (SARS-CoV-2), which is endangers the entire planet, was activated prior to January 2020, when its pathogenicity exploded in China. It starts as a minor outbreak in Wuhan, (may be elsewhere) that did not succeeded to mature as an epidemic. Tracking of origin of its zoonosis proved that its reservoirs were bats. Transition between the limited outbreaks in 2019 and the pandemic of December-January was possible by the general negative status that caused the preceding minor outbreaks. Global spread was predictable. The unpredicted issue was its transition, simply from epidemic to pandemic. Increased transmissibility has been caused by a mutation in the spike protein of the SARS-CoV-2.

SARS-CoV-2 appears as a new strain with no human immunity (rapid spread, higher morbidity and mortality, and exceeds medical services needed for serious illness). Corona strains similarities and world-wide pandemic indicate that infection control measures are well- reiterated and the present 
technologies should be speeded to introduce new lines of treatment and even vaccinations. ${ }^{4}$

The outbreak of chest infection in Wuhan occurred in $12 / 2019$. A new coronavirus was discovered in $1 / 2020$ (2019-nCoV). WHO declared it as a source of pneumonia in man. Since this pandemic, the entire world obligated to react with severe pandemic. There was deficiency in critical care beds, ventilators, infusion fluids, and protective measures of medical staff and patients from intra-hospital exposure and viral transmission. COVID-19 resulted in high mortality rate of infected immune-compromised victims, as those with chronic debilitating diseases and polypharmacy. Also over-acceptable rate of morbidity and mortality amoung healthcare workers. ${ }^{5}$

Since the early phase of the pandemic, Operative theatres and other wards were converted to critically ill wards for advanced patients. Non-urgent, and noncancer Surgical lists of non-acute, non-malignant cases were postponed. All medical staff and trainee were reallocated in COVID wards. These ultimate doomed situations, augment the critical role of surgeons in the differentiation between infected and non-infected cases in bad need for emergency surgery. Surgeons needs safe environment to react for limitation of virus distribution in healthcare personals and to downgrade complications and death rates. The World Society of Emergency Surgery educational board (WSES) recommended in its paper entailing priorities of management of urgent surgical cases under COVID-19 pandemic environment for the safety of both the cases and medical personnel's. ${ }^{5}$

Mutation of the viruses occurs all the time. Most variations are inconsequential. Sometimes it may be harmful to the virus, and sometimes it makes the organism more aggressive. These types of mutations tend to dominate. Viruses with the most important changes called "variants of concern". They are observed with the closest concern by virologists, the different strains included: Delta which currently accounts for $99 \%$ of new Covid cases in the UK, Alpha which first identified in the UK and spread to about 50 countries and continue mutation, Beta which discovered in South Africa and spread to more than 20 countries, including UK, and finally Gamma which first recognized in Brazil and spread to 10 other countries, including UK. ${ }^{6}$

As regard to vaccination, about $28.3 \%$ of the global population underwent vaccination (one dose at least), and $14.6 \%$ is fully vaccinated (two doses). Globally, 4.14 billion doses have been administered. Each day, 37.72 million doses are given. In low-income countries down to $1.1 \%$ of people were vaccinated (Fig. 1). ${ }^{7}$

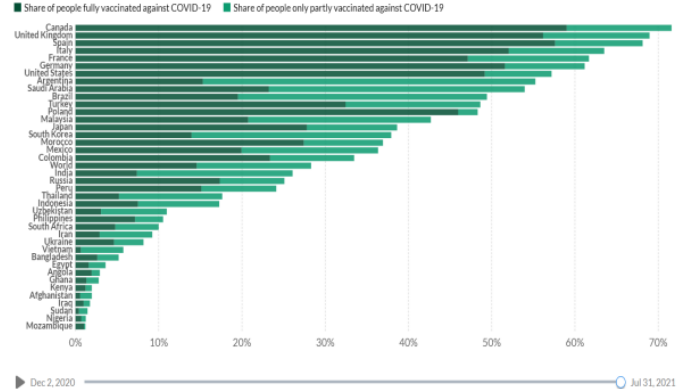

Fig. 1:Vaccination against COVID-19, Jul 31, $2021{ }^{7}$

\section{PATIENTS AND METHODS}

In the epidemic period from March 2018 to July 2021 folders of cases who performed urgent interference and go ahead were surveyed. Surgical operations implemented on cases required immediate interference after admission and those who needed immediate surgery during conservative follow-up in the emergency ward are classified as "emergency surgery". Cases who followed conservatively by surgeons in emergency ward were involved in the research for the test of four different periods. In response to complications, re-opened cases after elective interference were excluded from the study. Different data items were reviewed (demographic, number and type of operation, operative details, reexploration, complications and death rates were registered. "Pandemic Group" entails cases that performed urgent surgery in the pandemic era (2020 and 2021) and cases that performed urgent surgery in 2018 and 2019 were called "Control Group". Comparison of data was performed between pandemic and control groups (Fig. 2).

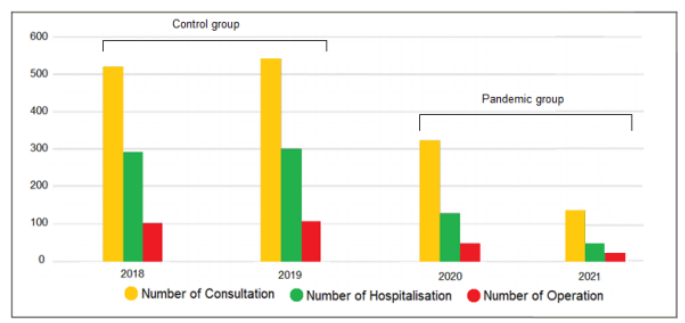

Fig. 2: Ratio of emergency consultation, hospitalization, and operation from March 2018 to July 2021.

Patients were investigated for COVID-19 infection as a secondary outcome. Pre-operative COVID-19 positive patients and postoperative hospital-induced COVID-19 infection were examined. Pre-operative CT chest was implemented in all cases who performed emergency operation (pandemic group). PCR test performed to cases with positive CT findings and those with clinical manifestations suggesting COVID-19. They were quarantined in the surgical ward. Patients suspected to have postsurgery COVID-19 manifestations underwent both PCR and CT chest. Healthcare professionals (operators, nurses, and workers) who were in direct contact with these patients were tested for COVID19.

In the present study we followed recommendations (WSES position paper) for surgical patients in 
the emergency situation of COVID-19 pandemic. Patients with epidemiologic and clinical manifestations suspecting COVID-19 were screened at emergency wards. Strongest recommendations were PCR naso-pharyngeal swab and a chest CT. Inconclusive chest X-ray or CT scan in patients' needs urgent surgery should be managed as COVID$19+$ ve patient to prevent spreading of the virus in the surgical theatres. Postoperatively, the questionable cases should be isolated till PCR result is obtained with further admission in COVID (+ve) or (-ve) wards.

Leucopenia with relative lymphocytopenia, elevated inflammatory biomarkers such as C-reactive protein, ESR, lactate dehydrogenase, creatinine, troponin I, fibrinogen, and D-dimer are the pathognomonic laboratory findings in COVID-19.

Artificial pneumo-peritoneum and viruses rich smoke from the equipment's of laparoscopy and laparotomy surgery make them as a highly risk procedures. It can be participate in intra-hospital viral spread duo to exposure to infected fluids, and generated smoke from electro-cautery.

TACS classification system (Timing of Acute Care Surgery) should be a valid guide for the detection of proper timing of interference and how severe the surgical disease is (Table 1$)^{8}$

\begin{tabular}{|c|c|c|c|}
\hline $\begin{array}{c}\text { Timing- iTTS } \\
\text { from diagnosis }\end{array}$ & Possible Clinical Scenarios(TACS) & $\begin{array}{c}\text { Color } \\
\text { code }\end{array}$ & Note \\
\hline $\begin{array}{c}\text { Immediate } \\
\text { surgery }\end{array}$ & Bleeding emergencies & $\begin{array}{c}\text { Immediate life saving surgical } \\
\text { intervention, resuscitative } \\
\text { laparotomy }\end{array}$ \\
\hline $\begin{array}{c}\text { Within an } \\
\text { hour }\end{array}$ & $\begin{array}{c}\text { Incarcerated hernia, perforated viscus, } \\
\text { diffuse peritonitis, soft tissue infection } \\
\text { accompanied with sepsis }\end{array}$ & $\begin{array}{c}\text { Surgical Intervention as soon } \\
\text { as possible but only after } \\
\text { resuscitation (within 1 } \\
\text { to 2 hours). administration of } \\
\text { antibiotics upon diagnosis- no } \\
\text { delay }\end{array}$ \\
\hline $\begin{array}{c}\text { Within 6 } \\
\text { hours }\end{array}$ & $\begin{array}{c}\text { Soft tissue infection (abscess) not } \\
\text { accompanied with sepsis }\end{array}$ & & $\begin{array}{c}\text { Administration of antibiotics } \\
\text { upon diagnosis- no delay }\end{array}$ \\
\hline $\begin{array}{c}\text { Within 12 } \\
\text { hours }\end{array}$ & $\begin{array}{c}\text { Appendicitis (local peritonitis), } \\
\text { cholecystitis (optional ) }\end{array}$ & & $\begin{array}{c}\text { Administration of antibiotics } \\
\text { upon diagnosis- no delay }\end{array}$ \\
\hline $\begin{array}{c}\text { Within 24 or } \\
48 \text { hours }\end{array}$ & Second-look laparotomy & $\begin{array}{c}\text { Schedule in advance. } \\
\text { Intervention should occur } \\
\text { during day time }\end{array}$ \\
\hline
\end{tabular}

Table 1: TACS classification. ${ }^{8}$

Intuitive paradigms and common knowledge caught by urgent care operators were challenged by the collected experience on the effect of delaying urgent operations on patient outcomes. Results of multiinstitutional prospective studies become clear about the need to detect the appropriate time of surgery for surgical emergencies.

\section{RESULTS}

Through the two eras of the present work, 770 patients were included in the study $(590+180), 293$ cases $(102+116+50+25)$ underwent emergency surgery and 477 patients $(188+184+80+25)$ were observed non-operatively. There was $37 \%$ of the patients $(102+116 / 590)$ underwent surgery in the control group and $42 \%$ of the pandemic group $(50+25 / 180)$ underwent surgery. There was a $65.6 \%$ (143/218) reduction in the number of emergency surgeries and $61.4 \%(267 / 372)$ decrease in observational managed cases in the pandemic group. The and Number of the cases who performed surgery for acute cholecystitis, complicated hernia, GI bleeding, and perforations in the two groups were statistically insignificant plus demographic data were summarized in Table 2.

The rate of surgery in the pandemic group was statistically higher in cases admitted for AMIO (acute mechanical intestinal obstruction) (Table 2). There was a severe decline in the number of cases admitted with AMIO. When the etiological factors were investigated, adhesive bowel obstruction admissions was low in the pandemic group $(70-12)$. There were fewer surgeries for incarcerated hernia (70 to 19) in the pandemic group; also there was no significant difference among cases that performed small bowel resection between the two groups (Table 2).

The number of patients admitted for acute cholecystitis during the pandemic period, decreased by $9.7 \%$ (4/46). In the control group the rate of operations was higher, although it was statistically insignificant (Table 2). There was $64.5 \%$ reduction in the number of cases who performed appendectomy (80/124) in the pandemic group. Uncomplicated appendicitis admissions were declined by $80.8 \%$ $(126 / 156)$. The number of cases who performed appendectomy for complicated appendicitis was statistically higher in the pandemic group (Table 2). Postoperative morbidity and reoperations were equal in the two groups. Mortality was statistically higher in the pandemic group (Table 3 ).

Findings diagnostic for COVID-19 in the preoperative evaluation were observed in chest $\mathrm{CT}$ of $16(8.9 \%)$ cases (secondary outcome). Five cases were documented as positive by PCR test $(2.8 \%)$ of these cases. Consultation with infectious diseases specialists started immediately and these patients received COVID-19 medication protocol. There was no mortality among these patients. One case with no initial COVID-19 manifestations, found to have COVID-19 infection observed in CT chest during postoperative intensive care period. This patient was PCR negative. He categorized as ASA 4 (American Society of Anesthesiologists). The patient died on the 7 th postoperative day. None of the healthcare professional including surgeons (12 worker and 6 surgeons) participating in urgent surgeries were COVID-19 infected. COVID-19 virus was found in two $(16.7 \%)$ healthcare professional belonging to the ward. 


\begin{tabular}{|c|c|c|c|c|c|}
\hline Patients & \multicolumn{2}{|c|}{ Control group } & \multicolumn{2}{|c|}{ Pandemic group } & $\mathrm{P}$ value \\
\hline \multirow{3}{*}{$\begin{array}{l}\text { Total } \\
\text { Year } \\
\\
\quad \text { Hospitalized, n (\%) } \\
\\
\text { Operated upon, n (\%) }\end{array}$} & \multicolumn{2}{|c|}{$590(100 \%)$} & \multicolumn{2}{|c|}{$180(100 \%)$} & \multirow[t]{3}{*}{0.342} \\
\hline & 2018 & 2019 & 2020 & 2021 & \\
\hline & $\begin{array}{c}290(100 \%) \\
102(35 \%)\end{array}$ & $\begin{array}{c}300(100 \%) \\
116(39 \%)\end{array}$ & $\begin{array}{l}130(100 \%) \\
50(38.5 \%)\end{array}$ & $\begin{array}{c}50(100 \%) \\
25(50 \%)\end{array}$ & \\
\hline $\begin{array}{l}\text { Age }(\text { mean } \pm \text { SD) } \\
\text { Gender: Male, } \mathrm{n}(\%) \\
\text { Female, } \mathrm{n}(\%)\end{array}$ & \multicolumn{2}{|c|}{$\begin{array}{c}42.3 \pm 12 \\
340(58 \%) \\
250(42 \%)\end{array}$} & \multicolumn{2}{|c|}{$\begin{array}{c}38.6 \pm 18.4 \\
112(62 \%) \\
68(38 \%)\end{array}$} & $\begin{array}{l}0.740 \\
0.852\end{array}$ \\
\hline $\begin{array}{l}\text { Acute appendicitis: } \\
\text { Surgery performed, } \mathrm{n}(\%) \\
\text { Conservative follow-up, } \mathrm{n}(\%)\end{array}$ & \multicolumn{2}{|c|}{$\begin{array}{c}280(47.6 \%) \\
124(44 \%) \\
156(56 \%)\end{array}$} & \multicolumn{2}{|c|}{$\begin{array}{l}74(41.1 \%) \\
44(59.5 \%) \\
30(40.5 \%)\end{array}$} & $0.002 *$ \\
\hline $\begin{array}{l}\text { Acute cholecystitis: } \\
\text { Surgery performed, } \mathrm{n}(\%) \\
\text { Conservative follow-up, } \mathrm{n}(\%)\end{array}$ & \multicolumn{2}{|c|}{$\begin{array}{c}46(7.9 \%) \\
6(13 \%) \\
40(87 \%)\end{array}$} & \multicolumn{2}{|c|}{$\begin{array}{l}42(23.2 \%) \\
6(14.3 \%) \\
36(85.7 \%)\end{array}$} & 0.083 \\
\hline $\begin{array}{l}\text { Complicated hernia: } \\
\text { Repair, no resection, n (\%) } \\
\text { Repair with resection, n }(\%) \\
\text { Conservative follow-up, n (\%) }\end{array}$ & \multicolumn{2}{|c|}{$\begin{array}{c}162(27.6 \%) \\
66(40.7 \%) \\
4(2.5 \%) \\
92(56.8 \%)\end{array}$} & \multicolumn{2}{|c|}{$\begin{array}{c}38(21 \%) \\
18(47.4 \%) \\
1(2.6 \%) \\
19(50 \%)\end{array}$} & 0.185 \\
\hline $\begin{array}{l}\text { Acute mechanical intestinal obstruction: } \\
\text { Surgery performed, } \mathrm{n}(\%) \\
\text { Conservative follow-up, } \mathrm{n}(\%)\end{array}$ & \multicolumn{2}{|c|}{$\begin{array}{l}70(11.9 \%) \\
12(17.1 \%) \\
58(82.9 \%)\end{array}$} & \multicolumn{2}{|c|}{$\begin{array}{l}12(6.8 \%) \\
3(25 \%) \\
9(75 \%)\end{array}$} & $0.034 *$ \\
\hline $\begin{array}{l}\text { GI bleeding: } \\
\text { Surgery performed, } \mathrm{n}(\%) \\
\text { Conservative follow-up, n (\%) }\end{array}$ & \multicolumn{2}{|c|}{$\begin{array}{c}18(3.2 \%) \\
2(11 \%) \\
16(89 \%)\end{array}$} & \multicolumn{2}{|c|}{$\begin{aligned} 12 & (6.8 \%) \\
1 & (8 \%) \\
11 & (92 \%)\end{aligned}$} & 0.732 \\
\hline $\begin{array}{l}\text { Perforations: } \\
\text { Duodenal ulcers, } \mathrm{n}(\%) \\
\text { Small intestine, } \mathrm{n}(\%) \\
\text { Colon, } \mathrm{n}(\%)\end{array}$ & \multicolumn{2}{|c|}{$\begin{array}{l}4(0.8 \%) \\
2(50 \%) \\
1(25 \%) \\
1(25 \%)\end{array}$} & \multicolumn{2}{|c|}{$\begin{array}{l}2(1.1 \%) \\
2(100 \%) \\
0(00 \%) \\
0(00 \%)\end{array}$} & 0.854 \\
\hline
\end{tabular}

Table 2: Distribution of the patients who performed urgent operation and cases that conserved medically.

\begin{tabular}{|l|c|c|c|}
\hline \multicolumn{1}{|c|}{ Morbidity and mortality } & $\begin{array}{c}\text { Control group 590 } \\
(100 \%) \mathrm{n},(\%)\end{array}$ & $\begin{array}{c}\text { Pandemic group 180 } \\
(100 \%) \mathrm{n},(\%)\end{array}$ & P value \\
\hline Wound infection & $20(3.4 \%)$ & $7(3.9 \%)$ \\
Wound dehiscence & $7(1.2 \%)$ & $5(2.8 \%)$ \\
Intra-abdominal abscess & $13(2.2 \%)$ & $7(3.9 \%)$ \\
Anastomotic leakage & $7(1.2 \%)$ & $5(2.8 \%)$ \\
Ileus & $11(1.8 \%)$ & $9(5 \%)$ \\
Postoperative bleeding & $7(1.2 \%)$ & $3(1.7 \%)$ \\
Urinary complications & $5(0.8 \%)$ & $3(1.7 \%)$ \\
Pulmonary complications & $13(2.2 \%)$ & $9(5 \%)$ \\
Cardiovascular complications & $10(1.7 \%)$ & $5(2.8 \%)$ \\
\hline Re-operation & $14(2.4 \%)$ & $10(5.4 \%)$ & 0.218 \\
\hline Total postoperative complications & $107(18.1 \%)$ & $63(35 \%)$ & $0.038^{*}$ \\
\hline Mortality & $7(1.19 \%)$ & $9(5 \%)$ & \\
\hline
\end{tabular}

Table 3: Outcome of emergency surgery.

\section{DISCUSSION}

Healthcare practices showed dramatic changes all over the world after COVID-19 spread. New guidelines have been published by medical professional societies as regard management of nonCOVID-19 disorders. ${ }^{9}$ Elective procedures have been postponed by surgeons in many healthcare facilities except for cancer cases and surgical emergency. Different surgical operations have also been a subject of various modifications during this period. ${ }^{10-12}$ whereas very emergency and emergency cases have been operated on immediately, semi-emergency cases have been operated on only after evaluation and approve of triage committees.

Most of the published literature on emergency surgery during the pandemic consists of reviews, expert recommendations, and guidelines; very few studies have yet reported the outcomes of altered clinical practices. In the present report, the outcomes of emergency cases managed at single hospital during the pandemic. After the first documented 
$10 \%$ of the cases still +ve even after 33 days of onset. $^{16}$

From the clinical point of view hospital discharge of uncertain, clinically suspected, or confirmed cases of COVID-19 (asymptomatic or mild symptomatic) may be considered as an appropriate decision following surgical recovery. In response to WHO justifications, in confirmed COVID-19 infection clinical standards for hospital discharge are :3 days of normal temperature (no use of fever-reducing drugs). ${ }^{15}$ Considerably relieved respiratory manifestations. Fundamental CT chest ameliorated acute exudative lesions. Two repeated negative PCR test with 1-day interval. CDC recommended that ${ }^{16}$, in the case of elderly patient's isolation if appropriate care providers are ready at house, the patient could be discharged.

For limiting exposure risk for other members of the family, infected member can be isolated in private room with adequate ventilation, wearing of face mask, prevention of close contact with other family members, feeding separate meals, proper sanitation, with absolute prohibition of outdoor efficacy. Of ultimate importance there should be no home members who may catch infection with increased possibility of COVID-19 complications such as old age $>65$ years, pregnant women, children, immunecompromised persons, or patients with chronic heart, lung, liver or kidney diseases. Family members should be adherent to advised precautions to avoid catching the virus until transmission risk is minimal.

Meticulous planning and major consultation are needed in the present circumstances for decision making to undergo elective and emergency surgical procedures. All patients should be suspected as COVID-19 +ve and should undergo pulmonary imaging before their urgent surgical interference unless proven otherwise - ve. ${ }^{17}$ Nowadays, guidelines for the treatment of acute cholecystitis and appendicitis (as both treated traditionally surgically), have drastically modified. Viral spread facilitated through aerosols disseminated with $\mathrm{CO}_{2}$ circulation within the abdominal cavity during laparoscopic surgery. So, laparoscopic GIT surgery in a patient with COVID-19 is considered highly risky. ${ }^{18}$

Patel et al. ${ }^{19}$ encysted that most of the patients diagnosed as appendicitis should receive parenteral broad spectrum antibiotics $(65 \%)$. Non responders who had manifestations of appendicular complications (35\%) were treated through open surgery (as regard to national guidelines). ${ }^{17}$ Recurrent uncomplicated appendicitis reached 27\% with conservative management. The safest option to treat appendicitis is antibiotics during these matchless periods. ${ }^{20,21}$ Also, all cases of acute cholecystitis presented in the outbreak time managed with parenteral broad spectrum antibiotics diverging from well-known practical guidelines of laparoscopic Cholecystectomy within the first few days of the attack. $^{22}$

Peoples' situations and behaviors adjusted during this short time period represent the early phase of the lockdown time. The long standing effects of medical services reduction and delays in essential surgical interference are well seen. So, the manner and gravity of clinical presentations are also changed.

Urgent surgery declined by $65.6 \%$ in the pandemic time. Highest decline occurred in acute cholecystitis, uncomplicated appendicitis and incarcerated hernia. Patients underwent surgical interference for acute mechanical intestinal obstruction, GIT perforation and GIT system bleeding, were identical in both groups. An increase in the number of surgeries during pandemic was observed in complicated appendicitis and acute mechanical intestinal obstruction. Mortality rate was higher in cases underwent urgent surgery in the pandemic time.

ESTES (European Society of Trauma and Emergency Surgery) recommended that the treatment of trauma and urgent surgical procedures must be the same as in the non-pandemic time. ${ }^{23}$ This recommendation was followed in the present study, the number of urgent interference showed significant decrease in the era of pandemic. Gallego et al. ${ }^{24}$ stated that the number of surgical emergencies during the era of pandemic declined from 3.6 to 1.6 per day. The current study showed that incarcerated hernia, acute cholecystitis, and uncomplicated appendicitis surgeries were mostly influenced by the pandemic insult. Decline in surgeries for acute cholecystitis and uncomplicated appendicitis may be explained by more antibiotics used during pandemic or many patients have improved with symptomatic management during quarantine. Laparoscopic appendectomy still the gold standard management for uncomplicated acute cholecystitis and appendicitis, therapy with antibiotics is a respectable option. ${ }^{25,26} \mathrm{~A}$ multi-center study by Tankel et al. ${ }^{27}$ stated that acute appendicitis admissions reduced by $40 \%$ during the pandemic, and concluded that cases with noncomplicated appendicitis recovered with medical therapy at house. Though there was a $72.9 \%(51 / 70)$ decline in the surgeries for incarcerated hernias. The sector of the cases' needs small intestinal resection and anastomoses still the same. The performed urgent operations due to mesenteric ischemia, perforation, and GIT bleeding were not changed by the pandemic. Feature of these urgent surgical diseases is that they are in the ambulatory type that needs immediate interference within hours. High mortality shown if early interference is postponed. ${ }^{28}$ Madelona et al. ${ }^{29}$ stated that in spite of the decline in general urological urgent intervention, total number of admissions requiring immediate surgery such as acute obstructive pyelonephritis, acute obstructive renal injury testicular torsion did not declined. This study revealed that patients who are in bad need for urgent surgery are admitted to the hospital during pandemic.

Complicated appendicitis and acute mechanical intestinal obstruction surgeries rose significantly during the pandemic era. Report by Gallego et al. ${ }^{24}$ underwent four appendectomies in twenty days in the pandemic (all patients proved to have complicated appendicitis). A multicenter study stated that surgical interference for acute mechanical intestinal obstruction increased in the pandemic. ${ }^{30}$ In the current study, one of the causes for increased performance of acute mechanical intestinal 
obstruction was the $82.9 \%(58 / 70)$ decrease in hospitalization for adhesive bowel obstruction (nonoperative treatment was effective). World Society of Emergency Surgery stated that in the absence of peritonitis or bowel ischemia this group should be managed conservatively. Success rates ranged from 60 to $90 \% .^{31}$ The most important result of this work is that although the reoperation and morbidity rates were equal in cases that underwent urgent surgery between both eras. Mortality rate increased during pandemic episode. Cano-Valderrama et al. $^{30}$ stated that morbidity rate was increased in cases that performed urgent interference during the pandemic. Reoperation and mortality percentages were equal. This is explained by delayed admission during the pandemic. Delayed treatment in a multicenter paper recorded > $40 \%$ of abdominal emergencies (nontraumatic) during pandemic. ${ }^{32}$

De Simone et al. ${ }^{33}$ stated that conservative measures can be stratified to acute cholecystitis, acute appendicitis, and adhesive bowel obstruction and obstructed hernias in pandemic era. Another report by East et al. ${ }^{34}$ recommended taxis approach for irreducible groin hernias as a safe primary technique in case where operative therapy is not immediate, as COVID-19 pandemic. There were marked decline in the number of cases who needed non-operative observation in up to date publications during pandemic. Surgeons wonder if outpatient observation is conceivable in these groups, where non-operative follow is feasible to meet the increasing bed demands on hospitalization.

The success of the protective measures taken against COVID-19 pandemic was investigated as a secondary outcome. Pre-admission chest CT was performed in all patients who were candidates for urgent surgery. PCR was not used as a routine test due to delayed outcome. ESTES advocated that delay in PCR results might affect the critical timing of surgical management. ${ }^{35}$ Some papers accounted that chest CT is more sensible than PCR. ${ }^{36,37}$ Patients with clinical suspicion and positive CT insult should be isolated and tested with PCR. Specific theater and elevator are only permitted for cases with COVID-19 suspicion. Surgical team absolutely wears masks, and face shields during operations of these patients. Measures taken in line with the recommendations of ESTES prohibit members of the surgical team from contact with infected patients. ${ }^{35}$ Abu Shakra et al., study detected $12(24 \%)$ of the surgical team gained infection with COVID-19. ${ }^{38}$

Important restriction of the present work is that it is single-center purpose. Final outcomes may not be generally applied to all medical centers. Admission of cases should be directed to less risky hospitals. For the reliability of these results comprehensive national and international studies are needed. Treatment of the cases comprising proper inquiries as CT and control schedules must be individualized according to the reviewing operator.

\section{CONCLUSION}

Screening for COVID-19 is highly recommended in all surgical patients who need immediate care. They are candidates for approval and emergency surgery. PCR nasopharyngeal swab test and chest CT are recommended, depending on availability and experience. Multidisciplinary task is needed for the management of COVID-19 surgical patients. It is highly recommended to protect theater staff, for the safety of the patient if an immediate intervention is mandatory, whether laparoscopic or open. Patients with acute cholecystitis and uncomplicated appendicitis should be treated with antibiotics and followed-up on outpatient bases. Taxis procedure may be successful in irreducible hernias. The longterm outcomes of patients are required to identify and matching those managed preservative during COVID-19 pandemic with those treated operatively. Discharged cases with medical treatments should be matched for morbidity and needs for readmissions. Global study may help in risk correspondence and detection of the cohort of cases appropriate for remote follow-up.

\section{REFERENCES}

1. Balkhair AA. COVID-19 pandemic: a new chapter in the history of infectious diseases. Oman medical journal. 2020; 35(2): 123.

2. Yen-ChinLiu, Rei-LinKuo, Shin-RuShih. COVID19: The first documented coronavirus pandemic in history. Biomedical Journal. 2020; 43(4): 328-33.

3. Platto S, Wang Y, Zhou J, Carafoli E. History of the COVID-19 pandemic: origin, explosion, worldwide spreading. Biochemical and biophysical research communications. 2021; 538: 14-23.

4. Chaplin S. COVID-19: a brief history and treatments in development. Prescriber. 2020; 31(5), 23-28.

5. De Simone B, Chouillard E, Sartelli M, Biffl WL, Di Saverio, S, Catena F. The management of surgical patients in the emergency setting during COVID-19 pandemic: the WSES position paper. World Journal of Emergency Surgery, 2021; 16(1): 1-34.

6. Fares W, Chouikha A, Ghedira K, Gdoura M, Rezig D, Boubaker, Triki H. Whole genome sequencing and phylogenetic analysis of six SARS-CoV-2 strains isolated during COVID19 pandemic in Tunisia, North Africa. BMC genomics. 2021; 22(1): 1-6.

7. https://ourworldindata.org/covid-vaccinations

8. Kluger Y, Ben-Ishay O, Sartelli M, Ansaloni L, Abbas AE, Agresta F, Moore E. World society of emergency surgery study group initiative on Timing of Acute Care Surgery classification (TACS). World Journal of Emergency Surgery. 2013; 8(1): 1-6.

9. American Collage of SurgeonCOVID-19: Elective case triage guidelines for surgical care. 2020.

10. COVID Surg Collaborative. Global guidance for surgical care during the COVID-19 pandemic. Br J Surg. 2020; 107(9): 1097-103. 
11. Søreide K, Hallet J, Matthews JB, Schnitzbauer AA, Line PD, Lai PBS. Immediate and longterm impactof the COVID-19 pandemic on delivery of surgical services. Br J Surg. 2020 Sep; 107(10):1250-61.

12. Di Saverio S, Pata F, Khan M, Ietto G, Zani E, Carcano G. Convert to open: the new paradigm for surgery during COVID-19?. Br J Surg. 2020; 107:e194.

13. Song F, Zhang X, Zha Y, Liu W. COVID-19: Recommended sampling sites at different stages of the disease. J Med Virol. 2020; 92:1383-1385.

14. Gombar, S., Chang, M., Hogan, C. A., et al Persistent detection of SARS-CoV-2 RNA in patients and healthcare workers with COVID19. Journal of Clinical Virology. 2020; 129: 104477.

15. World Health Organization. Coronavirus disease (COVID-19) advice for the public. https://www.who.int/emergencies/diseases/nov el-coronavirus-2019/advice-for-public

16. Discontinuation of Transmission-Based Precautions and Disposition of Patients with SARS-CoV-2 Infection in Healthcare Settings. Updated,

2021.

https://www.cdc.gov/coronavirus/2019ncov/hcp/disposition-hospitalized-patients.html

17. Royal College of Surgeons of England. Updated Intercollegiate General Surgery Guidance on COVID-19. Guidance for surgeons working during the pandemic. https://www.rcseng.ac.uk/coronavirus/jointguidance-for-surgeons-v2/

18. Di Saverio S, Pata F, Gallo G, Carrano F, Scorza A, Sileri P, Smart N, Spinelli A Pellino G. Coronavirus pandemic and colorectal surgery: practical advice based on the Italian experience. Colorectal disease. 2020; 22 (6): 625-34.

19. Patel R, Hainsworth AJ, Devlin K, Patel JH, Karim A. Frequency and severity of general surgical emergencies during the COVID-19 pandemic: single centre experience from a large metropolitan teaching hospital. The Annals of the Royal College of Surgeons of England. 2020; 102(6): 457-62.

20. Salminen $P$, Paajanen $H$, Rautio $T$, et al. Antibiotic therapy vs appendectomy for treatment of uncomplicated acute appendicitis: the APPAC randomized clinical trial. JAMA 2015; 313(23): 2340-8.

21. Sippola S, Haijanen J, Viinikainen L, et al. Quality of life and patient satisfaction at 7-year follow-up of antibiotic therapy vs appendectomy for uncomplicated acute appendicitis: a secondary analysis of a randomized clinical trial. JAMA surgery. 2020; 155(4): 283-89.
22. National Institute for Health and Care Excellence. Gallstone Disease: Diagnosis and Management. Clinical Guideline CG188. London: NICE; 2014.

23. Coimbra R, Edwards $\mathrm{S}$, Kurihara $\mathrm{H}$, et al. European Society of Trauma and Emergency Surgery (ESTES) recommendations for trauma and emergency surgery preparation during times of COVID-19 infection. European Journal of Trauma and Emergency Surgery. 2020; 46(3): 505-10.

24. Gallego MA, Casas SG de las, Migueláñez IP. Impacto de la pandemic por SARS-CoV-2 sobre la actividad y profesionales de un Servicio de Cirugía General y del Aparato Digestivo en un hospital terciario. Cirugía Española. 2020; 98: 320-7.

25. Di Saverio S, Podda M, De Simone B, et al. Diagnosis and treatment of acute appendicitis: 2020 update of the WSES Jerusalem guidelines. World journal of emergency surgery. $2020 ; 15(1): 1-42$.

26. Ansaloni L, Pisano M, Coccolini F, et al. 2016 WSES guidelines on acute calculous cholecystitis. World journal of emergency surgery. 2016; 11(1), 1-23.

27. Tankel J, Keinan A, Blich $\mathrm{O}$, et al. The decreasing incidence of acute appendicitis during COVID-19: a retrospective multi-centre study. World Journal of Surgery. 2020; 44(8):2458-63.

28. Kluger Y, Ben-Ishay O, Sartelli M, et al. World society of emergency surgery study group initiative on Timing of Acute Care Surgery classification (TACS). World Journal of Emergency Surgery. 2013; 8(1): 1-6.

29. Madanelo M, Ferreira C, Nunes-Carneiro D, et al. The impact of the coronavirus disease 2019 pandemic on the utilisation of emergency urological services. BJU int. 2020; 256-8.

30. Cano-Valderrama O, Morales X, Ferrigni CJ, et al. Acute care surgery during the COVID-19 pandemic in Spain: changes in volume, causes and complications. A multicentre retrospective cohort study. International Journal of Surgery. 2020; 80: 157-61.

31. Ten Broek RPG, Krielen P, Di Saverio S, et al. Bologna guidelines for diagnosis and management of adhesive small bowel obstruction (ASBO): 2017 update of the evidence-based guidelines from the world society of emergency surgery ASBO working group. World Journal of Emergency Surgery. 2018; 13(1): 1-13.

32. Patriti A, Baiocchi GL, Catena F, et al. Emergency general surgery in Italy during the COVID-19 outbreak: first survey from the real life. World Journal of Emergency Surgery. 2020; 15: 1-7. 
33. De Simone B, Chouillard E, Di Saverio S, et al. Emergency surgery during the COVID-19 pandemic: what you need to know for practice. The Annals of The Royal College of Surgeons of England. 2020; 102(5): 323-32.

34. East B, Pawlak M, de Beaux A. A manual reduction of hernia under analgesia/sedation (Taxis) in the acute inguinal hernia: a useful technique in COVID-19 times to reduce the need for emergency surgery-a literature review. Hernia. 2020; 24(3): 937-41.

35. Coimbra R, Edwards $\mathrm{S}$, Kurihara $\mathrm{H}$, et al European Society of Trauma and Emergency Surgery (ESTES) recommendations for trauma and emergency surgery preparation during times of COVID-19 infection. European Journal of Trauma and Emergency Surgery. 2020; 46(3), 505-10.

36. Fang Y, Zhang H, Xie J, et al. Sensitivity of chest CT for COVID-19: comparison to RTPCR. Radiology. 2020; 296 (2): 115-E117.

37. Ai T, Yang Z, Hou H, et al. Correlation of chest CT and RT-PCR testing for coronavirus disease 2019 (COVID-19) in China: a report of 1014 cases. Radiology. 2020; 296(2), 32-40.

38. Abu Shakra I, Bez M, Ganam S, et al. The volume of general surgery emergency cases in a government hospital during the COVID-19 pandemic and two other periods: a comparative, retrospective study. $B M C$ surgery. $2021 ; 21(1)$ : 1-6. 